\title{
PD15 - MP29-02 effectively relieves both nasal and ocular symptoms in adolescents aged 12-17 years: results from a meta-analysis of 4 randomised controlled Seasonal Allergic Rhinitis (SAR) trials
}

\author{
Erkka Valovirta ${ }^{1 *}$, Ruth Murray $^{2}$, Ullrich Munzel $^{3}$, Nikos Papadopoulos ${ }^{4}$ \\ From 3rd Pediatric Allergy and Asthma Meeting (PAAM) \\ Athens, Greece. 17-19 October 2013
}

\section{Introduction}

Two large paediatric studies are currently underway in the U.S. to investigate efficacy and safety of MP29-02 (Dymista) in children, with a view to extending its indication to those aged $\geq 6$ yrs. In line with FDA recommendations, these studies compare MP29-02 to placebo. To mimic the clinical trial design of these on-going pediatric studies, this meta-analysis assessed all data available for moderate-to-severe SAR patients aged 12-17 years, who received either MP29-02 or placebo in the same vehicle and device.

\section{Methods}

Data from 4 multi-centre, parallel-group, randomized, double-blind, placebo-controlled, 14-day studies were pooled. A total of 97 patients aged 12-17 yrs received MP29-02 (a novel intranasal formulation of azelastine hydrochloride and fluticasone propionate) 1 spray/nostril bid (total daily dose: AZE $548 \mu \mathrm{g}$; FP $200 \mu \mathrm{g}$ ) and 112 patients received placebo spray 1 spray/nostril bid. The primary efficacy variable was change from baseline over 14-days in reflective total nasal symptom score (rTNSS; AM + PM; MAX=24), the sum of 4 symptom scores for congestion, itching, rhinorrhoea and sneezing. Reflective total ocular symptom score (rTOSS; AM + PM; Max $=18$ ) was an important secondary endpoint.

\section{Results}

Patients aged 12-17 yrs treated with MP29-02 experienced a 4.29 point mean improvement from baseline
(18.7 [SD 2.7]) in their rTNSS, significantly more the 2.06 point improvement from baseline (18.7 [SD 2.8]) observed in those treated with placebo (diff: 2.23 ; $95 \% \mathrm{CI}$ : $3.23 ; 1.22 ; \mathrm{p}<0.0001$ ). Similarly, in this adolescent patient population treatment with MP29-02 produced a significant mean improvement in the rTOSS of 2.23 points from baseline (11.2 [SD 4.4]) compared to 1.04 points from baseline (10.9 [SD 4.0]) with placebo (diff: 1.19; 95\% CI: 2.06, 0.32; $\mathrm{p}=0.0080$ ).

\section{Conclusion}

These results show that adolescent SAR patients treated with MP29-02 experience significant relief from both their nasal and ocular symptoms. Similar beneficial effects may be expected in pediatric patients.

\section{Authors' details}

${ }^{1}$ Suomen Terveystalo Allergy Clinic, Turku, Finland. ${ }^{2}$ Medscript, Dundalk, Ireland. ${ }^{3}$ Meda, Bad Homburg, Germany. ${ }^{4}$ University of Athens, Athens, Greece.

Published: 28 February 2014

doi:10.1186/2045-7022-4-S1-P15

Cite this article as: Valovirta et al:: PD15 - MP29-02 effectively relieves both nasal and ocular symptoms in adolescents aged 12-17 years: results from a meta-analysis of 4 randomised controlled Seasonal Allergic Rhinitis (SAR) trials. Clinical and Translational Allergy 2014 4(Suppl 1):P15.

${ }^{1}$ Suomen Terveystalo Allergy Clinic, Turku, Finland

Full list of author information is available at the end of the article 